\title{
LETTERS
}

\section{Is having broad experience a red flag in the CaRMS match?}

It is counterintuitive that we had about 170 unmatched applicants in the Canadian Residency Matching Service (CaRMS) match in the first iteration of 2019, ${ }^{1}$ but at the same time 138 unfilled positions. ${ }^{2}$ Why can't these 170 applicants have a second choice when they are unmatched to their desired specialty?

One possible explanation is that applicants may feel pressured to focus on 1 specialty only. For instance, when applying to a competitive specialty, applicants may think they need to have all their elective clerkships tailored toward that specialty, in order that interviewers believe those applicants are very determined in their career plans. Although program descriptions on the CaRMS website state they welcome applicants with broad experience, applicants may be unfavourably judged when their electives are not focused. ${ }^{3}$

Having been in medical school and postgraduate training in the United Kingdom, I find this Canadian way of thinking a cultural shock. In the UK, we were all encouraged to have broad experience in various areas before going into a specialty.
Having hands-on experience in various medical services may be one of the best ways to learn effective handover, appropriate transfer of care to consulting services and respect toward other physicians, as listed under the CanMEDS collaborator role. ${ }^{4}$ As a patient, I would like my physician, specialist or not, to have broad knowledge and experience, rather than being too focused on only 1 area. I find it hard to believe CaRMS applicants are penalized for having broad experience.

Being a medical student may be the only time in a physician's career to develop a broad range of skills and knowledge. Whereas other graduate students are likely more than happy to have multiple skills before becoming principal investigators, medical students appear to be encouraged to have limited experience to make their specialty applications look strong.

I understand that residency programs do not want to be used as backdoor career options for some applicants. ${ }^{5}$ But loyalty works both ways: if a program interviews more applicants than the number of positions available, is it unreasonable for applicants to have backup plans?

Emphasis on focused experience in the CaRMS match has the potential to destroy not only the employability of applicants, but also the CanMEDS collaborator role.

\section{Eugene Y.H. Yeung MD MSc}

Resident physician, Department of Microbiology, University of Ottawa, Ottawa, Ont.

Cite as: CMAJ 2019 August 6;191:E869. doi: $10.1503 / \mathrm{cmaj} .72397$

\section{References}

1. McKeen A. 'Match day' places more med students, but number of new doctors without residencies still a concern. The Star [Vancouver] 2019 Feb 27. Available: www.thestar.com/news/canada/2019 /02/27/match-day-casts-fewer-medical-students -into-limbo.html (accessed 2019 Mar. 31).

2. Collier R. Family medicine again dominates unfilled positions in residency match. CMAJ 2019; 191:E322.

3. Woods A. Tragic case of Robert Chu shows plight of Canadian medical school grads. The Star [Quebec Bureau] 2017 June 17. Available: www.thestar.com/ news/canada/2017/06/17/tragic-case-of-robert-chu -shows-plight-of-canadian-medical-school-grads. html (accessed 2019 Mar. 31).

4. Royal College of Physicians and Surgeons of Canada. Collaborator. 2015. Available: www.royal college.ca/rcsite/canmeds/framework/canmeds -role-collaborator-e (accessed 2019 July 16).

5. Lerner J. Wanting family medicine without primary care. Can Fam Physician 2018;64:155-6.

Competing interests: None declared. 